\author{
Maria Borejszo \\ Uniwersytet im. Adama Mickiewicza w Poznaniu
}

\title{
Nazwy kolorów w leksyce odzieżowej (na materiale Słownika ubiorów Ireny Turnau)
}

Wydany dziesięć lat temu Słownik ubiorów autorstwa Ireny Turnau poza bogatym zbiorem leksyki odzieżowej (w ujęciu historycznym, to jest od XIV do początku XIX wieku) przynosi także dość obfity zbiór słownictwa określającego kolory, oczywiście głównie ubiorów i tkanin ${ }^{1}$. Ponieważ część zgromadzonego tam materiału nie jest dziś powszechnie znana i używana, nie zawsze też notują ją słowniki historycznej polszczyzny, warto przyjrzeć się jej dokładniej jako jednemu z wycinków pola językowego nazw barw w polszczyźnie, dotychczas w całości niezbadanemu².

Na wstępie trzeba odpowiedzieć na pytanie, jak liczny jest to zbiór. Otóż cały udokumentowany w Słowniku ubiorów materiał dotyczący nazw kolorów obejmuje 113 leksemów, w tym 102 wyrazy w formach podstawowych oraz 11 wariantów fonetycznych i pisowniowych. W zdecydowanej większości jest to, jak się wydaje, słownictwo o zasięgu ogólnopolskim, o różnym stopniu stabilizacji w języku, chociaż trafiają się także różnego typu archaizmy i formy dialektalne, np. fonetyczne (chwieletowy, chwiotkowy, fialutowy, jacynktowy, amarantowy), leksykalne (wasilkowy) ${ }^{3}$. Biorąc pod uwage pięćset lat dziejów

${ }^{1}$ I. Turnau, Stownik ubiorów. Tkaniny, wyroby pozatkackie, skóry, broń i klejnoty oraz barwy znane w Polsce od średniowiecza do poczatku XIX w., Warszawa 1999.

${ }^{2}$ Bibliografia dotycząca nazw barw w polszczyźnie jest dość bogata. Przykładowo można wymienić tu takie opracowania, jak: A. Zaręba, Nazwy barw $w$ dialektach $i$ historii języka polskiego, Wrocław 1954; M. Ampel-Rudolf, Kolory. Z badań leksykalnych i składniowo-semantycznych języka polskiego, Rzeszów 1994; R. Tokarski, Semantyka barw we wspótczesnej polszczyźnie, wyd. 2 rozszerz., Lublin 2004 (m.in. tam dalsza literatura przedmiotu).

${ }^{3}$ Cały zebrany materiał został zamieszczony w końcowej części artykułu. Tam też można znaleźć objaśnienia znaczeń poszczególnych wyrazów (por. indeks omawianych w artykule określeń kolorystycznych). 
polszczyzny objętych badaniami przez autorkę Stownika ubiorów, zbiór ten nie wydaje się zbyt licznie reprezentowany, a więc zapewne i kompletny. Nawet dość pobieżna obserwacja zgromadzonego materiału prowadzi do wniosku, że są to głównie wyrazy używane w polszczyźnie jedynie okresowo, być może nawet tworzone lub zapożyczane okazjonalnie dla zaspokojenia potrzeb związanych z panująca w danym momencie modą. Około $37 \%$ leksemów badanego zbioru nie zostało bowiem udokumentowanych w największych słownikach dawnej i współczesnej polszczyzny, takich jak: Stownik staropolski pod redakcją Stanisława Urbańczyka, Stownik polszczyzny XVI wieku pod redakcją Marii Renaty Mayenowej, Stownik języka polskiego Samuela Bogumiła Lindego, Stownik języka polskiego (tzw. wileński), Stownik języka polskiego (tzw. warszawski), Stownik języka polskiego pod redakcją Witolda Doroszewskiego $^{4}$, a niekiedy nawet w szczegółowych monografiach poświęconych nazewnictwu kolorów w polszczyźnie różnych epok (por. Alfred Zaręba, Ryszard Tokarski).

Jak wynika z informacji wstępnych, Stownik ubiorów obejmuje 3761 nazw, w tym 2705 leksemów w formie zdefiniowanych haseł i 1056 terminów synonimicznych i obocznych ${ }^{5}$. Jest to zatem, jak do tej pory, najobszerniejsze opracowanie leksyki odzieżowej w formie słownikowej, bazujące na badaniach prowadzonych przez autorkę opracowania nieprzerwanie niemal przez pół wieku' ${ }^{6}$.

W zgromadzonym materiale wyraźnie wyodrębniającą się grupę tworzą zapożyczenia funkcjonujące $\mathrm{w}$ polszczyźnie na zasadzie słabo przyswojonych lub w ogóle nieprzyswojonych cytatów. Są to m.in. takie określenia kolorów, jak: celeste (wł. celeste 'niebieski')', chamois (fr. chamois 'płowożółty'), depis, depuis (fr. puce 'pchła; kolor ciemnobrązowy'), dorato (wł. dorato 'złotawy, złocisty'), giallo (wł. giallo 'żółty'), granato (por. wł. granato 'ziarnisty; krzew lub niskie drzewo z rodziny granatowcowatych; twardy minerał,

${ }^{4}$ Stownik staropolski, red. S. Urbańczyk, t. 1-11, Wrocław-Kraków 1953-1995 (dalej skrót: Sstp); Stownik polszczyzny XVI wieku, red. M.R. Mayenowa, t. 1-32, Wrocław-Warszawa 1966-2004 (dalej: SPXVI); S.B. Linde, Stownik jezzyka polskiego, t. 1-6, wyd. 2 popr. i pomnożone, Lwów 1854-1860; wyd. fotooffsetowe, Warszawa 1994-1995 (dalej: SL); Stownik języka polskiego, red. A. Zdanowicz et al., t. 1-2, Wilno 1861 (dalej: SWil); J. Karłowicz, A. Kryński, W. Niedźwiedzki, Stownik języka polskiego, t. 1-8, Warszawa 1900-1927; wyd. fotooffsetowe, Warszawa 1952-1953 (dalej: SW); Stownik języka polskiego, red. W. Doroszewski, t. 1-10, Warszawa 1958-1968, t. 11: Suplement, Warszawa 1969 (dalej: SD).

${ }^{5}$ I. Turnau, op.cit., s. 5.

${ }^{6}$ Pierwszy słowniczek objaśniający wydawnictwo źródłowe, zredagowany przez Irenę Turnau, ukazał się w 1959 roku.

${ }^{7}$ We wszystkich przywoływanych w artykule przykładach zachowuję oryginalną pisownię. Wyjątek stanowi jedynie leksem gotembiaty, pojawiający się równolegle z przymiotnikiem gotębi, którego zapis ujednolicam (gotębiaty). 
zwykle barwy czerwonawej', od łac. pomum granatum 'owoc ziarnisty; granat'), gridelino (wł. gridellino 'liliowy', por. fr. gris de lin 'szarolniany'), kokilko (fr. coquelicot 'kolor makowy'), lila (fr. lilas 'liliowy, jasnofioletowy'), pallie (fr. paillé 'słomkowy'), pons // ponso / punzo (fr. ponceau 'pasowy'), verdepom // verdepon / werdepom // werdepon (fr. vert de pomme 'zielone jabłko'). Część spośród wymienionych leksemów pojawia się równolegle w postaciach bardziej spolonizowanych, z typowym dla przymiotników sufiksem -owy, np.: gryalinowy // gryglinowy, paliowy, werdeponowy ${ }^{8}$.

Do określeń kolorów przejętych ze źródeł obcych, słabo w polszczyźnie zaadaptowanych i używanych jedynie okresowo należą także leksemy: celadynowy (fr. céladon 'seledynowy') ', cygrynowy (niem. seegrün 'morskozielony'), feltmortowy (fr. feuille-morte 'koloru zwiędłych liści'), inkarnatowy (por. łac. incarnatus 'cielisty; jasnoczerwony', fr. incarnat 'wiśniowy', wł. incarnatino 'jasnoróżowy, cielisty'), izabelowy (fr. couleur isabelle 'kolor brunatnożółty, płowy'), kaffowy (por. wł. caffè 'kawa', fr. café 'kawa; kolor kawowy, ciemnobrązowy'), morderowy (fr. mordoré 'złocistobrązowy'), walensowy (fr. valence 'pomarańcza walencka') ${ }^{10}$. Zapożyczeniem dobrze utrwalonym w polszczyźnie, używanym co najmniej od czasów średniowiecza jest przymiotnik błękitny, przejęty z języka czeskiego (stczes. blankytný 'jasnoniebieski')11.

Większość udokumentowanych w Słowniku ubiorów określeń kolorystycznych została utworzona w polszczyźnie od podstaw rodzimych lub zapożyczonych za pomocą przymiotnikowego sufiksu -owy (około 54\% zebranego materiału), np.: agatowy, amarantowy, barszczowy, blamarantowy (!), brzoskwiniowy, chwieletowy, chwiołkowy, ciatkowy, cynamonowy, czekuladowy, farforkowy, fialutowy, fiałkowy, grynszpanowy, indychtowy, jabłonkowy, jacynktowy, jamarantowy, kaczorowy, kaparowy, kapucynowy, krokosowy, lawendowy, lazurowy, liliowy, majowy, marcepanowy, oliwkowy, orzechowy, perłowy, pieprzowy, piernikowy, pijusowy // piusowy, pizowy, pokrzywkowy, porcelanowy, prochowy, rosotkowy, rozmarynowy, rożynkowy (!), sasankowy, sosenkowy, susowy (!), szafranowy, tabaczkowy, turkusowy, wasilkowy. Inne formacje sufiksalne pojawiają się znacznie rzadziej, np.: -ny (bławatny, obłoczny, ołowny), -aty (gołębiaty, jałowaty), -niczy (jabłonniczy), -asty (papuzasty), -owaty (moragowaty, pieprzykowaty). Sporadycznie dokumentowane

${ }^{8}$ W polszczyźnie znane są też wyrazy granatowy 'kolor owocu granatu; kolor ciemnoniebieski', liliowy czy pqsowy, których nie odnotował Słownik ubiorów Turnau (por. SD).

${ }^{9}$ Formą współcześnie używaną jest, wywodzący się z tego samego źródła, przymiotnik seledynowy. Być może w grę wchodzi tu jedynie różnica pisowniowa, a nie wymawianiowa.

${ }^{10}$ Por. Wielki słownik francusko-polski, t. 2, red. J. Dobrzyński, A. Dutka, B. Frosztęga et al., wyd. 7, Warszawa 2003, s. 928.

11 Por. W. Boryś, Słownik etymologiczny języka polskiego, Kraków 2005. 
są również derywaty paradygmatyczne, typu: gołębi, muszy, papuzi, rydzy, czy formacje złożone, np.: bladoróżowy, gorqcożółty, żółtogorqcy Aurora, czerwień ksiażęca, czerwień turecka, liturgiczne kolory, saski kolor.

Poza formacjami o przejrzystej budowie słowotwórczej występują także struktury stare, zleksykalizowane, odziedziczone z języka prasłowiańskiego czy nawet praindoeuropejskiego, takie jak: $d z i k i^{12}$, modry, siny, siwy, szady.

Część nazw kolorów związanych z modą pojawia się w formach nieustabilizowanych, wariantywnych (np.: amarantowy // blamarantowy // jamarantowy, bławatny // bławy, chwiołkowy // fiałkowy, ciałkowy // cielisty, depis // depuis, gołębi // gołębiaty, gorqcożótty // żóttogoracy Aurora, gridelino // gryalinowy // gryglinowy, jabłonkowy // jabłonniczy, lila // liliowy, paliowy // pallie, papuzi // papużasty, pieprzowy // pieprzykowaty, pijusowy // pius // piusowy, pons // ponso / punzo, szarłat // szkarłat, verdepom // verdepon // werdepom // werdepon // werdeponowy // werdysan), co można tłumaczyć faktem, że Słownik ubiorów uwzględnia materiał z bardzo szerokiego przedziału czasowego (od średniowiecza do początku XIX wieku), mogą się w nim zatem pojawiać tzw. warianty chronologiczne wyrazów, czy też tym, że obok leksyki ogólnopolskiej znalazły się tam także pojedyncze regionalizmy, a nawet dialektyzmy. Poza tym znaczna część wyrazów należy do zapożyczeń i to zapożyczeń o różnym stopniu adaptacji językowej w polszczyźnie.

W zebranym materiale liczebnie dominują określenia barwy czerwonej o różnych odcieniach, np.: amarantowy, barszczowy ${ }^{13}$, bladoróżowy, blamarantowy, ciatkowy, cielisty, czerwień ksiqżęca, czerwień turecka, granato, inkarnatowy, jabłonkowy, jabłonniczy, jamarantowy, karmazyn, kokilko, pons, ponso, punzo, rydzy, sosenkowy, szarłat, szkarłat ${ }^{14}$. Nieco mniej liczne są nazwy oznaczające kolor żółty (np.: brzoskwiniowy, chamois, dorato, dziki ${ }^{15}$, feltmortowy, giallo, gorqcożótty, izabelowy, jałowaty, krokosowy, paliowy, pallie, rosołkowy, saski kolor ${ }^{16}$, siarczysty, szafranowy, walensowy, żółtogoracy Aurora) $)^{17}$, niebieski (np.: bławatny, bławy, błękitny, celeste, indychto-

12 Słownik ubiorów podaje jako formę hasłową postać rodzaju żeńskiego dzika (barwa).

13 W tym miejscu warto odnotować, że przymiotnik ten stosowany był w polszczyźnie dla określenia dwóch odrębnych kolorów: czerwonego (kolor czerwonego buraczanego barszczu) i zielonego (ciemnozielony kolor liści rośliny o nazwie barszcz). Por. SPXVI, SD.

14 Niektóre spośród cytowanych przykładów oznaczają barwy pośrednie, np.: ciałkowy, cielisty, rydzy, sosenkowy.

15 SPXVI przymiotnik $d z i k i$ identyfikuje z barwą ciemnoczerwoną, ciemnobrunatną, a nie żółtopłową, jak I. Turnau (por., ,jako z czarnej i białej farby bywa szara, a z czarnej a czerwonej dzika”, CzechRozm 23). SL, SWil i SW zestawienie dzika farba objaśniają jako 'żelazną farbę, koloru żelaznego'.

16 SW zestawienie kolor saski odnosi do barwy jasnozielonej, a nie żółtej, jak Irena Turnau.

17 Część wymienionych przykładów oznacza barwy o różnych odcieniach lub kolory definiowane w Słowniku ubiorów Turnau jako pośrednie (np.: brzoskwiniowy, chamois, dziki). 
wy, jacynktowy, lawendowy, lazurowy, modry, obłoczny, rozmarynowy, siny, siwy, susowy, turkusowy, wasilkowy) ${ }^{18}$ i zielony (np.: celadynowy, cygrynowy, grynszpanowy, kaparowy, majowy, oliwkowy, papuzi, pokrzywkowy, verdepom, verdepon, werdepom, werdepon, werdeponowy, werdysan $)^{19}$.

Pozostała paleta barw nie odgrywa już zapewne tak istotnej roli w badanej grupie leksykalnej (chodzi o słownictwo związane z modą, głównie z ubiorami i tkaninami), przynajmniej z historycznego punktu widzenia, ponieważ reprezentują ją znacznie mniej liczne przykłady. W grę wchodzą tu przede wszystkim określenia barw szaro-brunatnych i brązowych (np.: agatowy, brunatny ${ }^{20}$, cynamonowy, czekuladowy, depis, depuis, gołębi, gotębiaty, kaczorowy, kaffowy, kapucynowy, morderowy, muszy, ołowny, orzechowy, pieprzowy, pieprzykowaty, piernikowy, pijusowy, pius, piusowy, prochowy, rożynkowy, szady, tabaczkowy), a także fioletu (np.: chwieletowy, chwiołkowy, fialutowy, fiałkowy, lila, sasankowy) i bieli (np.: farforkowy, gridelino, gryalinowy, gryglinowy ${ }^{21}$, liliowy ${ }^{22}$, marcepanowy, perłowy, porcelanowy). Pojedyncze przykłady nazywają też połączenia kilku kolorów, np.: moragowaty, papużasty, pizowy.

Jak wynika z obserwacji, udokumentowany w Słowniku ubiorów zestaw barw jest mało zróżnicowany. Obejmuje bowiem zaledwie dziewięć subpól kolorystycznych (czerwień, żółć, kolor niebieski, zielony, szary, brunatny, brązowy, fioletowy, biały). Może to wskazywać, że w naszej historii szczególną popularnością cieszyły się ubiory o określonej kolorystyce (np. barwy stanowe) lub też - co wydaje się bardziej prawdopodobne - że udokumentowany w wykorzystanym leksykonie zestaw nazw nie oddaje całego bogactwa leksyki kolorystycznej związanej z dawną polską modą 23 .

Przy określaniu kolorów odzieży i tkanin najczęściej odwoływano się do charakterystycznych realiów, najczęściej dobrze znanych z codziennej obserwacji otaczającego człowieka świata, np. szczególnie często wykorzystywano odniesienia do świata flory (np.: amarantowy, brzoskwiniowy, chwiołkowy,

${ }^{18}$ Część przykładów należy do określeń niejednoznacznych lub nazw barw pośrednich (np.: celeste, jacynktowy, lawendowy, siwy).

${ }_{19}$ Przymiotnik oliwkowy może oznaczać różne odcienie barwy zielonej: od zielonożółtej, przez żółtozieloną, aż do brunatnej.

${ }^{20}$ Nazwą tą, zgodnie z objaśnieniem Ireny Turnau, określano początkowo kolor przejściowy pomiędzy błękitem i czerwienią. Dopiero od XIX wieku przymiotnik ten wyspecjalizował się w znaczeniu 'brązowy'.

${ }^{21}$ Nazwą tą oznaczano barwę niebielonego lnu, czyli szarawą biel, a także kolor jasnoniebieski.

${ }^{22}$ Dawniej wyraz ten oznaczał kolor białokremowy, jak kwiat lilii, a później kolor różowofioletowy, lila.

${ }^{23}$ Dla porównania można podać, że Alfred Zaręba, autor monografii poświęconej nazwom kolorów w dialektach i historii języka polskiego, nazw tych zgromadził znacznie więcej. 
fiałkowy, indychtowy, jabłonkowy, jabłonniczy, jacynktowy, jamarantowy, kaparowy, krokosowy, lawendowy, liliowy, majowy, oliwkowy, orzechowy, pokrzywkowy, rozmarynowy, rydzy, sasankowy, sosenkowy, wasilkowy) i fauny (np.: gołębi, gotębiaty, jałowaty, kaczorowy, muszy, papuzi, papużasty), a także do leksyki z dziedziny kulinariów (np.: barszczowy, cynamonowy, czekuladowy, kaffowy, marcepanowy, pieprzowy, pieprzykowaty, piernikowy, rosolkowy, rożynkowy, szafranowy). Znacznie mniej przykładów nawiązuje do barw innych desygnatów, np. kamieni półszlachetnych, minerałów, metali, klejnotów (agatowy, lazurowy, olowny, perlowy, siarczysty, turkusowy), zjawisk atmosferycznych (obłoczny, szady), ubiorów noszonych przez konkretnych ludzi lub grupy ludzi (izabelowy, kapucynowy, pijusowy, pius, piusowy, saski kolor), różnych wytworów człowieka (farforkowy, porcelanowy) ${ }^{24}$.

Zbierając informacje dotyczące określeń kolorystycznych udokumentowanych w Stowniku ubiorów Ireny Turnau, trzeba stwierdzić, że ich liczba nie wydaje się szczególnie duża, jeżeli weźmie się pod uwagę fakt kilkusetletniej historii polszczyzny w jej pisanej odmianie i zasób różnorodnych tekstów źródłowych zachowanych do czasów współczesnych. Można domniemywać, że autorka leksykonu postawiła sobie za zadanie udokumentowanie i objaśnienie przede wszystkim wyrazów rzadko współcześnie w polszczyźnie używanych bądź też nieużywanych w ogóle, ale robi to - jak wynika z obserwacji - nie zawsze konsekwentnie, skoro obok nazw rzeczywiście rzadkich lub nieznanych pojawiają się też takie określenia kolorystyczne, jak: bladoróżowy, błękitny, brzoskwiniowy, golębi, liliowy, oliwkowy, orzechowy, perłowy, siwy, turkusowy ${ }^{25}$.

Pewne zdziwienie, zwłaszcza historyka języka, może budzić brak rozgraniczenia słownictwa o zasięgu ogólnopolskim od postaci niewątpliwie dialektalnych. Fakt ten przestaje jednak zaskakiwać, gdy weźmie się pod uwagę to, że Irena Turnau jest historykiem ubioru, a nie leksykografem i opracowany przez nią Słownik ma m.in. pomóc czytelnikom tekstów źródłowych, będących z wykształcenia historykami, a nie filologami, we właściwym odbiorze i w interpretacji zachowanych zabytków.

Zebrany w Stowniku ubiorów materiał pochodzi z prowadzonej przez autorkę kwerendy źródłowej, przede wszystkim w inwentarzach ruchomości

${ }^{24} \mathrm{Na}$ grupy leksyki szczególnie predestynowane do stawania się podstawami słowotwórczymi nazw kolorów zwraca uwagę m.in. R. Tokarski (op.cit., s. 148-149).

${ }^{25}$ We wstępie do Stownika ubiorów pojawia się informacja, że celem pracy było przedstawienie jak najpełniejszego zbioru informacji o ubiorach w całej ich barwności i bogactwie, noszonych przez ludzi różnych stanów, zamieszkujących ziemie dawnej Rzeczypospolitej, Śląska i Pomorza. Autorka, jak pisze, postanowiła objaśnić staropolskie nazwy barw i liczne ich odcienie, odbiegające znacznie od nazw współczesnych (I. Turnau, op.cit., s. 5). 
i testamentach, a także w rachunkach i danych cechowych wraz z taksami towarów. Łącznie wyekscerpowano około 1950 spisów mienia szlacheckiego, 2900 mieszczańskiego i ponad 200 chłopskiego, pochodzących z XVI-XVIII wieku ${ }^{26}$. Użytkowy, a nie literacki charakter wykorzystanych w pracy Ireny Turnau źródeł bez wątpienia wpłynął na zasób i zróżnicowanie uzyskanej tą drogą leksyki. Trzeba pamiętać, że tego typu spisy sporządzali ludzie o różnym poziomie wykształcenia, z pewnością niedysponujący szeroką wiedzą i świadomością językową, stąd mieszanie leksyki ogólnopolskiej z gwarową, rodzimej z obcą. Byli to też chyba mężczyźni, a nie kobiety, a więc osoby być może mniej zainteresowane modą czy kolorystyką opisywanych realiów.

U językoznawcy pewien niepokój może wywoływać pominięcie w Stowniku jakichkolwiek odniesień źródłowych, zwłaszcza w wypadku wyrazów nieudokumentowanych do tej pory $\mathrm{w}$ żadnych opracowaniach leksykograficznych, co uniemożliwia choćby bardzo orientacyjne usytuowanie w czasie przywoływanego materiału, a także ustalenie, w jakim typie tekstów wyrazy te się pojawiły. W uwagach wstępnych autorka zaznacza wprawdzie, że przy wszystkich niemal nazwach starała się podać czas, kiedy były one w użyciu, a brak tego rodzaju informacji świadczy o funkcjonowaniu nazw w całym badanym okresie, czyli od XIV do początku XIX wieku, ale w praktyce przyjęta zasada nie zawsze jest stosowana, przynajmniej w odniesieniu do określeń kolorystycznych ${ }^{27}$.

Mimo zauważonych braków zgromadzony w Słowniku materiał wydaje się godny uwagi, ponieważ pozwala przynajmniej częściowo uzupełnić luki w badanym polu leksykalno-semantycznym. Można też mieć nadzieję, że w przyszłości przynajmniej niektóre zauważone braki i niedociagnięcia będzie można poprawić lub uzupełnić po opracowaniu i wydaniu Stownika polszczyzny XVII i 1. połowy XVIII wieku. W wypadku badanego pola leksykalnego trzeba też brać pod uwagę fakt, że wiele określeń może mieć charakter okazjonalny, nieustabilizowany w języku. Część zgromadzonych w Słowniku nazw należy zapewne do indywidualizmów językowych, tworzonych doraźnie dla nazwania nowych trendów w modzie lub też raczej, jeśli weźmie się pod uwagę charakter wykorzystanych przez autorkę tekstów źródłowych, w celu prawidłowego zidentyfikowania przedmiotów inwentarskiego opisu.

\footnotetext{
26 Ibidem, s. 7.

27 Ibidem, s. 6.
} 


\section{Indeks omawianych w artykule określeń kolorystycznych ${ }^{28}$}

Agatowy 'kolor naturalnego, niebarwionego agatu, tj. szary lub brunatny', amarantowy 'kolor ciemnoróżowy, czerwonawy, czerwony z odcieniem fioletowym', barszczowy 'czerwień buraczanego barszczu', bladoróżowy 'kolor kwiatu dzikiej róży', blamarantowy 'kolor czerwonawo-różowy, rozbielony', btawatny 'od XV wieku kolor niebieski, nasycony', bławy 'kolor niebieskawy, zbliżony do bławatu', błękitny 'kolor jasnoniebieski, nienasycony', brunatny 'kolor przejściowy, pomiędzy błękitem a czerwienią (dopiero w XIX wieku brązowy)', brzoskwiniowy 1) 'źółtawy kolor owocu brzoskwini', 2) 'bladoróżowy, jak kwiat jej zwyczajnej odmiany', 3) 'potocznie, niewłaściwie - kolor jasnołososiowy', celadynowy 'seledynowy, czyli kolor rozbielonej zieleni', celeste 'kolor jasnoturkusowy', chamois 'kolor skóry zamszowej, żółtopłowy', chwieletowy p. fiatkowy, chwiolkowy p. fiatkowy, ciatkowy p. cielisty, cielisty 'kremoworóżowy, kolor naśladujący jasną karnację skóry białej kobiety', cygrynowy 'kolor morskiej zieleni', cynamonowy 'kolor rdzawobrązowy', czekuladowy 'kolor jasno- lub ciemnobrązowy', czerwień ksiażęca 'kolor czerwony o szczególnym odcieniu uzyskanym przez połączenie kermesu $\mathrm{z}$ barwnikiem niebieskim', czerwień turecka 'barwnik czerwony używany od dawna na Bliskim Wschodzie i w południowej Rosji (od XVI wieku znany pod nazwą krapu)', depis 'kolor pchli, ciemnobrunatny, modny w XVIII wieku', depuis p. depis, dorato 'kolor złocisty', dziki 'barwa mieniąca się dwoma kolorami osnowy i wątku, w odcieniach umaszczenia dzikiej zwierzyny, a więc

${ }^{28}$ Znaczenia przywoływanych w indeksie leksemów pochodzą ze Słownika ubiorów Turnau. Drukiem pogrubionym oznaczam wyrazy nienotowane w podstawowych leksykonach języka polskiego lub notowane tam w znaczeniach niezwiązanych z określeniami barw (por. SStp, SPXVI, SL, SWil, SW, SD). Niekiedy mogą to być postaci dialektalne. Część wyróżnionych wyrazów odnotował wcześniej A. Zaręba w cytowanej monografii (por. ciałkowy, rozmarynowy). W pracy A. Zaręby nie zostały odnotowane w funkcji nazw kolorów następujące leksemy: agatowy, barszczowy, bladoróżowy, blamarantowy, celadynowy (jest seledynowy), celeste, chamois, chwieletowy (jest fioletowy), chwiołkowy (jest fiołkowy), cynamonowy, czekuladowy (jest czekoladowy), czerwień ksiązęca (jest czerwień), czerwień turecka, depis, depuis, dorato, dziki (jest dzikie wino), farforkowy, feltmortowy, fialutowy (jest fioletowy), fiałkowy (jest fiołkowy), giallo, gołębiaty, goracożółty, granato (jest granat i granatowy), gryalinowy (jest grialinowy), inkarnatowy, jabłonkowy, jabłonniczy, amarantowy, kaczorowy, kaffowy (jest kafowy i kawowy), kaparowy, kapucynowy, lawendowy (jest lawenda), liturgiczne kolory, marcepanowy, muszy, ołowny, orzechowy, pallie (jest paillé), papuzi, papużasty (jest papuziasty), pieprzowy, pieprzykowaty, piernikowy, pijusowy (jest piusowy), pius, pizowy, pokrzywkowy, pons (jest ponso), porcelanowy, prochowy, punzo, rosołkowy, rożynkowy (jest rozynkowy), sasankowy, saski kolor, sosenkowy, susowy, szarłat, szkarłat (jest szkarłatny), verdepom (jest verd de pont), verdepon, walensowy, wasilkowy, werdepom, werdepon, werdeponowy, werdysan, żółtogorqcy Aurora. 
żółtopłowa'29, farforkowy 'kolor białawy porcelany lub fajansu', feltmortowy 'w XVIII wieku kolor żółtobrązowy, zeschłych liści', fialutowy p. fiałkowy, fiałkowy 'w języku staropolskim kolor brunatny, czyli przejściowy pomiędzy barwami niebieską i czerwoną (dopiero w XIX wieku terminem brunatny zaczęto określać odcień koloru brązowego)', giallo 'kolor żółty', gołębi 'kolor szaroniebieski', gotębiaty 'kolor zgaszonego fioletu, występujący miejscowo w upierzeniu gołębi' ${ }^{30}$, gorqcożółty 'od XVI wieku barwa żółta najbliższa czerwieni', granato 'kolor intensywnej, żywej czerwieni, jak kwiat, miąższ lub sok granatu', gridelino p. gryglinowy, gryalinowy p. gryglinowy, gryglinowy 'barwa niebielonego lnu, czyli szarawa, także kolor jasnoniebieski', grynszpanowy 'kolor grynszpanu, czyli zielony', indychtowy 'kolor granatowy', inkarnatowy 'kolor bladoróżowy, cielisty lub bardziej nasycony - rozkrojonego mięsa - modny w XVIII wieku', izabelowy 'niezdecydowany kolor brudnożółty długo niepranej białej odzieży’, jabłonkowy p. jabłonniczy, jabłonniczy 'kolor różowawy, jak kwiat dzikiej jabłoni', jacynktowy 'kolor szafirowy', jałowaty 'kolor jałówki, żółtawopłowy, czerwonawy', jamarantowy p. amarantowy, kaczorowy 'ciemny, szarobrunatny kolor jak upierzenie dzikich kaczek', kaffowy 'kolor ciemnobrunatny, kawowy', kaparowy 'ciemny, zgniłozielony kolor marynowanych kaparów', kapucynowy 'ciemnobrązowy jak barwa habitu kapucyna', karmazyn 'kolor nasyconej czerwieni dojrzałej maliny, uzyskany z kermesu lub koszenili', kokliko 'czerwień kwiatu maku', krokosowy 'kolor żółty', lawendowy 'kolor niebieskofioletowy lub fioletowy jak kwiaty lawendy', lazurowy 'niebieski, nasycony jak barwa lazurytu', lila 'kolor kwiatu lilaka, czyli bzu, różowofioletowy lub jasnofioletowy', liliowy 1) 'dawniej kolor białokremowy jak kwiat lilii', 2) 'potocznie jasny kolor różowofioletowy, lila', liturgiczne kolory 'używane w szatach kościelnych kolory: biały, czerwony, zielony, fioletowy i czarny', majowy 'kolor wiosennej zieleni', marcepanowy 'kolor marcepanu, biały o chłodnym, szklanym odcieniu beżowo-piaskowy, złotawy', modry 'kolor szafirowy, nasycony niebieski', moragowaty 'pręgowany, pasiasty, pstry', morderowy 'kolor złocistobrązowy, czerwonobrunatny', muszy 'kolor muchy, czyli bury', obłoczny 'w XVI wieku określenie koloru jasnoniebieskiego', oliwkowy 'kolor oliwek: od zielonożółtego, przez żółtozielony, aż do brunatnego', ołowny 'koloru ołowiu', orzechowy 'jasnobrązowy kolor okrywy orzecha', paliowy 'kolor bladożółty, jak słoma', pallie p. paliowy, papuzi 'kolor majowej zieleni', papużasty 'określenie jaskrawego zestawienia barw w tkaninach o osnowie i wątku w kontrastujących kolorach', perłowy 'kolor kredowobiały z połyskiem', pieprzowy

\footnotetext{
29 Por. przypis 12

30 Por. przypis 7.
} 
'kolor pieprzu, niezdecydowany szaroczarny', pieprzykowaty p. pieprzowy, piernikowy 'kolor ciemnobeżowy lub żółtobrązowy', pijusowy p. piusowy, pius p. piusowy, piusowy 'kolor brązowy z odcieniem fioletu', pizowy 'pstry', pokrzywkowy 'kolor zielony w odcieniu liści pokrzywy', pons (!) 'kolor pąsowy, ciemnoczerwony, zgaszony', ponso p. pons, porcelanowy 'kolor białawy', prochowy 'kolor ciemnografitowy', punzo p. pons, rosolkowy 'kolor „oczek” w rosole', rozmarynowy 'niezdecydowany niebieski odcień kwiatu rozmarynu', rożynkowy 'kolor rodzynek, jasnobrązowy lub brunatny', rydzy 'kolor rudy, czerwonożółty', sasankowy 'kolor fioletowoszary', saski kolor 'kolor żółty (od barwy liberii na dworze Sasów)', siarczysty 'kolor siarki, ostrożółty z czerwonawym odcieniem', siny 'kolor niebieski z niewielką domieszką czerwieni', siwy 'w XV wieku określenie koloru niebieskofioletowego, ciemnoniebieskiego', sosenkowy 'kolor czerwonobrązowy, zbliżony do barwy pnia sosny', susowy 'kolor niebieski', szady 'kolor szarawy', szafranowy 'kolor szafranu, intensywnie żółty', szarłat p. szkarłat, szkarłat 'kolor ciemnoczerwony o czystym, głębokim tonie', tabaczkowy 'kolor tabaki, brązowy z zielonkawym odcieniem', turkusowy 'kolor czysto niebieski w odcieniu najlepszej odmiany turkusu', verdepom $\mathrm{p}$. werdepom, verdepon $\mathrm{p}$. werdepom, walensowy 'kolor pomarańczowy', wasilkowy 'kolor niebieski (termin używany na ziemiach wschodnich dawnej Rzeczypospolitej w XVII-XVIII wieku)', werdepom 'zielony kolor jabłka, modny w XVIII wieku', werdepon $\mathrm{p}$. wertepom, werdeponowy $\mathrm{p}$. werdepom, werdysan $\mathrm{p}$. werdepom, żóttogoracy Aurora 'kolor żółty z czerwonawym odcieniem'.

\section{Maria Borejszo \\ Designations of Colours in Clothing Lexis (on the basis of Stownik ubiorów ("The Dictionary of Clothing") by Irena Turnau}

The Dictionary of Clothing by Irena Turnau records 113 lexemes defining the colours of clothes and fabrics used in the Polish language from the 14th century until the beginning of the 19th century. The material collected by the author of the Dictionary originates from the sources that are seldom taken into account by lexicographers, that is from inventories, last wills, bills, the data recorded by guilds and merchandise official prices, and because of this a large group of words was not documented in the dictionaries of historical Polish and monographs devoted to the names of colours (in the index placed at the end of the article, such words have been highlighted with bold type).

In the analysed material, a quite numerous group of loan words (mainly from French and Italian) is represented, used in Polish only periodically, but also the vernacular formations, most often found with the suffix -owy, derived from the word-forming 
bases being the names of flora, fauna and cookery, precious and semiprecious stones, minerals, metals, atmospheric phenomena etc.

The names of various shades of red colour, then yellow, blue and green dominate among the lexical items describing the colours of clothes and fabrics. The remaining palette of colours is represented by fewer examples. We can include here such names of colours as: grey-brown, brown, violet and white.

The descriptions of the colours of clothes and fabrics contained in the Dictionary of Clothes by Irena Turnau, do not fully represent a whole richness of lexicon of the studied semantic field. It is also difficult to answer unambiguously the question about the reasons which decided about this specific selection of material, because, next to the names which were not documented previously, there appears here also the generally known vocabulary which has been in use in the Polish language until today. Also, the author does not separate the lexicon used all over Poland from dialectal names. 
